\title{
Die gesunde Zukunft
}

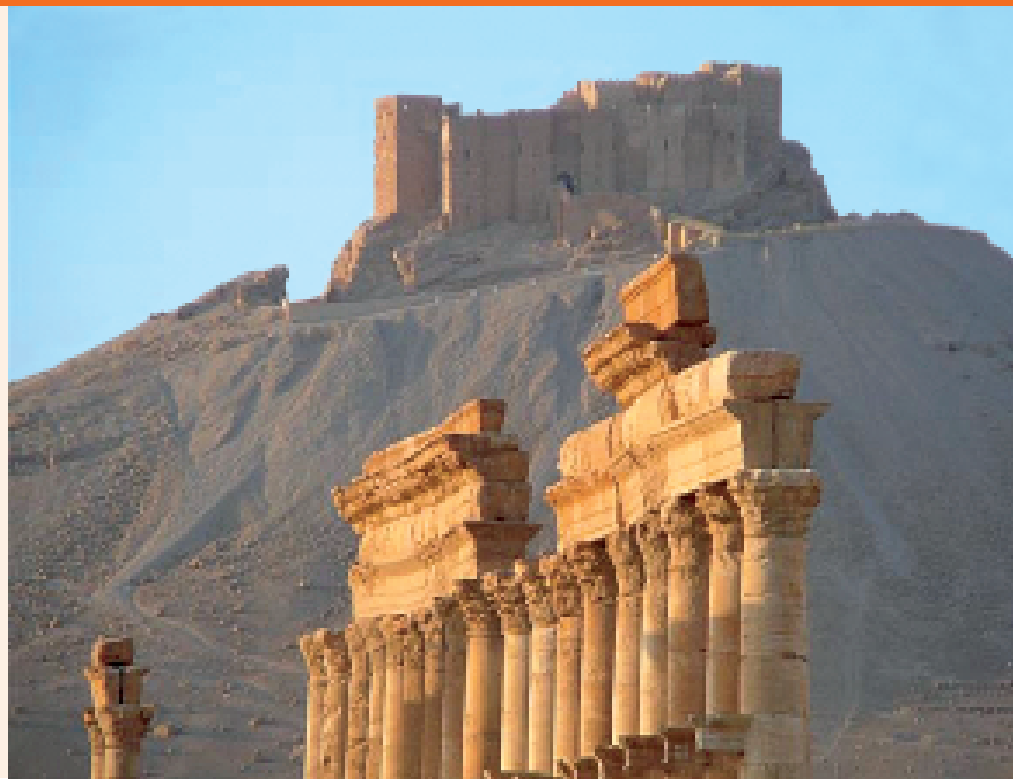

Gesundheit ist ein Politikum. Der Versorgerstaat erzieht seine Bürgerinnen und Bürger zu dem, was er für ein gesundes Leben hält. Mit Repression und Pädagogik erzwingt er das Glück: keine Drogen, kein Nikotin, Kalorienverbote, Fettsteuern, mehr Bewegung, keinen Alkohol, keine Pornographie usw. usf. Risikoprämien, Sozialabzüge und Strafen ergänzen den Schulunterricht, die Medienkampagnen, die Aufklärungstage, die privaten und öffentlichen Kontrollen. Das eigene Wohlbefinden soll die Arbeitskraft und damit die allgemeine Wohlfahrt fördern, ein Wechselspiel zum Vorteil aller.

Quer zu dieser Denkweise beklagt der Psychoanalytiker Peter Schneider das Verschwinden des Lasters, Zitat: «Die Leerstelle der Tugend hat mit Erfolg die Gesundheit besetzt.» Im satirischen Beitrag einer Tageszeitung zitiert er den Arzt Bernard Mandeville, der im frühen 18. Jahrhundert in den Untugenden des einzelnen und der Familie den Treibstoff der modernen Ökonomie zu erkennen glaubte. Widersprechen sich diese Auffassungen oder ergänzen sie sich? Vielleicht hilft ein Blick zurück in die wesensverwandte Renaissance. Aus dieser Zeit stammen drei berühmte Gesellschaftsentwürfe, in denen die staatlich verordnete Gesundheit eine bedeutende Rolle spielt.

A. «Utopia» von Thomas Morus (1478-1535).

Der Titel des fiktiven Reiseberichtes, verfasst vom Juristen und Lordkanzler des englischen Königs Heinrich VIII., gab dem Genre utopischer Modelle den Namen. Auf jener Insel in der neuen Welt wird ein Gegenbild der aktuellen britischen Verhältnisse gelebt. Die Utopier definieren die Tugend als ein naturgemässes Leben. Wer nach diesen Regeln handelt, lebt angenehm und fröhlich: «Lust nen- nen sie jede Regung und jeden Zustand des Leibes und der Seele, die naturgemäss auszukosten Genuss verschafft.» Bekömmlich ist, was die gesunde Vernunft anstrebt, und unter allen Freuden des Körpers steht die Gesundheit an erster Stelle. Die Insulaner sind beweglich und munter, kräftig und massvoll, nicht unansehnlich, ausdauernd, durchaus freizeitorientiert, aber immer lernfreudig. Kranke werden mit grosser Hingabe gepflegt, sind sie unheilbar und leidend, werden sie, wenn sie das wünschen, nach Anhörung durch die Priester und Behörden, mittels Einschläfern erlöst.

B. «Die Sonnenstadt» von Tommaso Campanella (1568-1639). Der Mönch und Dominikaner wurde in Süditalien wegen Ketzerei verhaftet und verbrachte die längste Zeit seines Lebens im Gefängnis. Seine Utopie ist die radikalste, weil der Staat über alles, auch über Eigentum, Gattenwahl und Fortpflanzung, bestimmt. Die Stadtbewohner sind hierarchisch rigoros in übersichtliche Wohngruppen unterteilt, in denen alles geteilt wird. Die Mauern sind mit Bildern bedeckt, die den Unterricht ergänzen und der andauernden und lückenlosen Belehrung dienen. Bekleidung, Hygiene, Kindererziehung, Arbeit und Fortpflanzung sind detailliert vorgeschrieben. Die Ernährung ist wichtig, viele werden hundert, manche sogar zweihundert Jahre alt: «Die Gesamtheit isst zweimal, die Kinder aber viermal, je nach Anordnung des Arztes.» Eine ausgeklügelte Gesundheitspflege sorgt für Leibesübungen und Genügsamkeit. Heilmittel und Bäder sind beliebt, geheime Mittel erneuern die Lebenskraft ohne Nebenwirkungen, «auf milde und wunderbare Art». 
C. «Neu-Atlantis» von Francis Bacon (15611626). Der Jurist, Baron und Lordkanzler unter dem König Jakob I. schrieb einen unvollendeten, romanhaften Reisebericht, wie er in seinem Jahrhundert besonders beliebt und verbreitet war. Auf der Insel im stillen Ozean blühen die Forschungsstätten und technischen Errungenschaften. Es gibt grosse unterirdische Höhlen und «Gemächer der Gesundheit» zur Heilung von Krankheiten, nebst einem ein «Paradieswasser», das Wohlbefinden und Langlebigkeit fördert. Bäder und Heiltränke stärken die Nerven. Bacon erwähnt Laboratorien zur Herstellung von Heilmitteln, optische, mechanische und akustische Werkstätten, die alle unsere Sinne verstärken. «Lichthändler» und «Beutesammler» durchkämmen das globale Wissen zu Gunsten eigener Experimente und Anwendungen, Automaten erleichtern die Arbeit und ein
«Haus der Blendwerke» stellt Trugbilder zu unterhaltenden und schulischen Zwecken her.

Manches dieser zeit- und ortlosen Beschreibungen einer idealen Zukunft erinnert an die Gegenwart. Die Betonung der Naturgesetze und der Macht des Wissens bis hin zur Tyrannei der Vernunft sind uns vertraut. Das goldene Zeitalter des Intellekts wird durch eine elitäre, absolute Staatspädagogik verwaltet, garantiert durch die Wächterschar des «guten Herrschers». Eine strenge Sittenlehre, theokratisch, astrologisch oder wissenschaftlich begründet, steuert das Triebleben und den Freiheitsdrang der Utopier. Ordnung, Arbeit, Wohlfahrt, Glück, Gerechtigkeit, Zwang, Freiheit und Tugend sind in dieser Welt nahezu identische Begriffe. Gemessen an den Staatstheorien der Renaissance herrscht bei uns vorläufig noch die Anarchie. 